\title{
Biological control of the Asian citrus psyllid, Diaphorina citri Kuwayama (Hemiptera: Liviidae) by Entomopathogenic fungi and their side effects on natural enemies
}

\author{
Ana Belén Corallo ${ }^{1 *} \mathbb{D}$, Evelin Pechi ${ }^{2}$, Lina Bettucci ${ }^{1}$ and Susana Tiscornia ${ }^{1}$
}

\begin{abstract}
Background: The Asian citrus psyllid, Diaphorina citri Kuwayama (Hemiptera: Liviidae) is an insect pest species responsible for damages of citrus fruit quality and tree health. This insect is a vector of bacteria 'Candidatus Liberibacter' spp. a putative causal agent of citrus greening disease known as Huanglongbing (HLB), considered one of the most destructive diseases of citrus orchards worldwide. Disease management is mainly based on vector control using pesticides which can affect natural enemies that play an important role in pest control. The entomopathogenic fungi (EPF) Beauveria bassiana (2067 and 2121) and Metarhizium anisopliae (2411) were achieved by applying a suspension of $1 \times 10^{7}$ spores against $D$. citri nymphs and artificially infected the citrus seedlings under controlled and semi-field conditions. Also, the activity of these EPFs on the coccinellid and lacewing predators was evaluated. The effects of the main chemicals used in citrus plantations on the selected fungi for possible combined use was also investigated.

Results: The obtained results showed that under controlled conditions, the percentage of insect mortality produced by EPF varied between 82.8 and $85.9 \%$. Under semi-field conditions, the infection and mortality of $D$. citri caused by the $M$. anisopliae 2411 strain was significantly higher than that of B. bassiana 2067, 78.9 and 51\%, respectively. Non-significant effect of EPF on the natural enemies of D. citri was observed, suggesting that EPF and predators had compatible effects.

Conclusion: This study clearly demonstrated that EPF were able to kill D. citri and can be explored as a promissory biocontrol candidate. Simultaneous use in an integrated pest management program could be possible by applying EPF combined with pesticides.
\end{abstract}

Keywords: Citrus, Huanglongbing, Diaphorina citri, Beauveria bassiana, Metarhizium anisopliae, Predators, Pesticides

\section{Background}

Citrus production in Uruguay has an important social and economic impact, 14107 ha of citrus have been planted, producing 242645 tons of fruits. About $43 \%$ of the production was exported, $33 \%$ was for internal consumption as fresh fruit and $22 \%$ was industrialized (DIEA 2019).

\footnotetext{
* Correspondence: belencfabiano@gmail.com

'Sección Micología, Facultad de Ciencias-Universidad de la República, Montevideo, Uruguay

Full list of author information is available at the end of the article
}

The Asian citrus psyllid, Diaphorina citri Kuwayama (Hemiptera: Liviidae), is a sap-sucking insect pest species, responsible for direct or indirect damages of citrus fruit quality and tree health. The insect feeds on sap sucking of younger leaves or buds and can inject toxins that produce deformations that can cause the death of the apical bud. They produce honeydew that allows the development of sooty mold in plants. Moreover, $D$. citri is a vector of bacteria 'Candidatus Liberibacter' spp., a putative causative agent of citrus greening disease, known also as Huanglongbing (HLB), considered one of 
the most destructive diseases of citrus worldwide (Bové 2006). The presence of the vector has been reported (Bernal 1991), but the HLB has not been found so far. However, the disease has been reported in the bordering countries of Brazil and Argentina (Lopes et al. 2013), denoting an imminent infection risk for Uruguay. Disease management is mainly based on the production of healthy plants, the eradication of diseased plants and vector control (Orduño-Cruz et al. 2015). This pest is the most often controlled by an excessive use of synthetic pesticides, which may increase the probability of developing resistance to pesticides (Tian et al. 2018; Naeem et al. 2019). On the other hand, it can affect natural enemies that play an important role in the pest's control. In addition, pesticide residues can remain in food causing a risk to food safety. International regulations are now increasingly restrictive with the maximum levels of pesticide residues allowed. The combined use of chemical pesticides and biological control emerges as an interesting strategy for sustainable management of $D$. citri (Qureshi et al. 2014). Natural enemies of D. citri include predators such as coccinellids (Coleoptera: Coccinellidae), lacewings (Neuroptera: Chrysopidae), syrphids (Diptera: Syrphidae) and spiders (Arachnida: Araneae), and the parasitoids such as Tamarixia radiata Waterston (Hymenoptera: Eulophidae) and Diaphorencyrtus aligarhensis Shafee, Alam \& Argarwal (Hymenoptera: Encyrtidae) and the EPF such as Isaria fumosorosea Wize, Lecanicillium lecanii (Zimm.) Zare \& W. Gams, Beauveria bassiana (Bals. -Criv.) Vuill and Hirsutella citriformis Speare (Lezama-Gutiérrez et al. 2012). Chrysoperla externa Shneider (Neuroptera: Chrysopidae) and Harmonia axyridis Palla (Coleoptera: Coccinellidae) are the main predatory species found on the citrus plantations of Uruguay (Pechi et al. 2016). EPF are extensively used as a biocontrol agent, and they act by contact and do not need to be ingested to infect their hosts. Their spores can be dispersed by biotic or abiotic factors, as horizontal transmission is possible and epizootics in the field can occur (Conceschi et al. 2016).

Hence, the aim of this work was to evaluate the potential of the EPF: B. bassiana and M. anisopliae isolates against $D$. citri biocontrol in citrus plantations and also to evaluate the effect of EPF on the coccinellid and lacewing predators and in turn to investigate the effect of the main chemicals used in citrus plantations on the selected fungi for possible combined use.

\section{Methods}

\section{Evaluation of $D$. citri fungal infection in citrus seedlings} under controlled conditions

Two strains of B. bassiana (2067 and 2121) and one of M. anisopliae (2411) were evaluated. The virulence of each fungal strain on $D$. citri was performed, using a suspension of $1 \times 10^{7}$ viable conidia/ml $0.02 \%(\mathrm{v} / \mathrm{v})$ Tween 80. Application of fungal suspension was carried out on 7-month-old citrus seedlings, artificially infected with different nymphal instars of $D$. citri. A total of 2132 individuals were obtained from the mass rearing of the Instituto Nacional de Investigación Agropecuaria (INIA) Salto Grande. Twenty-four pots, with 3 seedlings each, were used. For each selected fungal strain, $30 \mathrm{ml}$ of the conidial suspension was sprayed on the foliar surface of seedlings in each pot. Negative controls were sprayed only with $0.02 \%$ (v/v) Tween 80 . Six replicates (pots) were done per treatment. Each pot was covered with fine mesh that prevents the movement of insects from one pot to another. Plants were incubated at $25 \pm 2{ }^{\circ} \mathrm{C}$ for 5 days and then buds of treated and control seedlings were cut and investigated with a stereomicroscope. Living and dead individuals of nymphs were counted, and the presence of mycelium emerging from insects was recorded. Dead insects without evident presence of mycelium were transferred to individual moist chambers to determine if fungal infection had occurred. Insects were individually placed to avoid fungal transmission between samples and the overestimation of infection, as suggested by Hesketh et al. (2010). The percentage of insect mortality caused by fungi was calculated as the number of dead insects with the EPF/total of treated insects $\times 100$.

To evaluate if there are significant differences between insect mortalities, data were transformed as $\operatorname{arcsen} \sqrt{x}$ and Tukey's test was performed considering $\alpha=0.05$.

\section{Evaluation of insect infection under semi-field conditions}

To evaluate the insect infection under field conditions, a similar assay as mentioned before under controlled conditions was carried out. Seven-month-old citrus seedlings were artificially infected by nymphs of $D$. citri at different stages of development. A total of 1657 individuals were obtained from the mass rearing of INIA Salto Grande. For each fungus strain, 10 pots containing 3 seedlings each were inoculated. Surface of seedling leaves was sprayed by $30 \mathrm{ml}$ suspension of $1 \times 10^{7}$ viable conidia/ml $0.02 \%(\mathrm{v} / \mathrm{v})$ Tween 80 . The control was performed by applying $0.02 \%(\mathrm{v} / \mathrm{v})$ Tween 80 (10 pots with 3 infected seedlings each). Each pot was covered by a fine mesh to prevent exit of insects. All pots were placed randomly under the trees canopy interspersed inside a citrus plantation. After 5 days, the effect of the inoculation with EPF on D. citri infection was evaluated.

All living and dead individuals were counted by using a stereomicroscope. Dead insects were placed in a humid chamber to analyze fungal infection. Percentage of insect mortality caused by the fungi was calculated as the number of dead insects with EPF evidence/total of treated insects. To determine if there were significant differences in the mortality of $D$. citri between treatments, data were 
transformed as $\operatorname{arcsen} \sqrt{\mathrm{x}}$ and Tukey's test was performed considering $\alpha=0.05$.

\section{Effect of temperature on EPF}

Since the highest infection occurs in summer, where the temperature is highly variable, the conidial viability at different temperatures were evaluated. A conidial suspension of $1 \times 10^{3}$ conidia/ml $0.02 \%(\mathrm{v} / \mathrm{v})$ Tween 80 was inoculated on potato dextrose agar (PDA) culture medium (Oxoid ${ }^{\mathrm{TM}}$ ) and incubated at 15, 20, 25, 30, and $35^{\circ} \mathrm{C}$ for $20 \mathrm{~h}$ in the dark. Five replicates were tested, and 200 spores were counted per plate. Viability of spores was calculated as the germinated conidia/total conidia $\times 100$. A spore was considered viable, if the germinated tube reached $3 / 4$ the size of the spore. To evaluate if there were significant differences in spore germination at different temperatures, the transformation of the data was done as $\operatorname{arcsen} \sqrt{ } \mathrm{x}$ and Kruskal-Wallis test was performed considering $\alpha=0.05$.

\section{Evaluation of EPF incidence on the predators of $D$. citri} Breeding units of $C$. externa and $H$. axyridis were established in the Laboratorio de Entomología, Facultad de Agronomía-Universidad de la República, to supply individuals for the assays.

\section{Effect of EPF on $H$. axyridis}

Suspensions of spores of B. bassiana 2067 or M. anisopliae 2411 of $1 \times 10^{7}$ viable conidia/ml $0.02 \%(\mathrm{v} / \mathrm{v})$ Tween 80 were applied on the insects. The control was carried out by applying only $0.02 \%(\mathrm{v} / \mathrm{v})$ Tween 80 . The individuals were placed separately in cages provided with specific food. The larvae were placed individually to avoid cannibalism. The bioassay was kept for 7 days under controlled conditions of temperature $\left(24 \pm 2{ }^{\circ} \mathrm{C}\right)$. Three replicates of each assay were performed. A total of 207 individuals of $H$. axyridis were analyzed, 41 larvae and 166 adults. The insects that died in the trial were placed in a humid chamber to observe fungal infection. If fungal mycelium was present, microscopic observation was performed to confirm the presence of EPF. To determine if there were significant differences in the mortality rates of $H$. axyridis between treatments, data were transformed as arcsen $\sqrt{\mathrm{x}}$ and Dunn's test was performed considering $\alpha=0.05$

\section{Effect of EPF on C. externa}

Cages of C. externa larvae, with one individual per cage, were performed to avoid cannibalism. On the other hand, groups of adult individuals were placed in cages. In each cage, a wet cotton and yellow paper with eggs of Ephestia kuehniella (Lepidoptera: Pyralidae) as food was placed. Suspensions of $1 \times 10^{7}$ viable conidia/ml $0.02 \%$ (v/v) Tween 80 of B. bassiana and M. anisopliae were applied on the larvae and adult individuals of C. externa. In control cages, only $0.02 \%(\mathrm{v} / \mathrm{v})$ Tween 80 was applied on the insects. The bioassay was kept for 7 days under controlled conditions of temperature $\left(24 \pm 2^{\circ} \mathrm{C}\right)$. Three replicates of each assay were performed. A total of 321 individuals of C. externa were analyzed, 183 larvae and 138 adults. Dead or alive individuals were counted daily, and dead insects were placed in a humid chamber to corroborate the fungal infection. To determine if there were significant differences in the mortality rates of $C$. externa between treatments, data were transformed as arcsen $\sqrt{x}$ and a Dunn's test was performed considering $\alpha=0.05$.

\section{Effect of pesticides on selected EPF}

The effect of copper oxychloride, abamectin, and mineral oil products, the most frequently used in citrus plantations, on conidial germination and mycelial growth, was evaluated. Three concentrations $(350,500$, and 650), (1.75, 2.50, and 3.25), and (12.25, 17.50, and 22.75) for Abamectin $(\mu \mathrm{l} / \mathrm{l})$, copper oxychloride $(\mathrm{g} / \mathrm{l})$, and mineral oil $(\mathrm{ml} / \mathrm{l})$, respectively, were used, based on the concentration usually applied in the field and additionally + a concentration 30\% high and 30\% low.

Both copper oxychloride and mineral oil were incorporated into the PDA culture medium before autoclaving. Since abamectin is a very volatile compound, it was incorporated by filter-sterilization into the medium after the sterilization process. To determine the viability of the conidia in presence of copper oxychloride and abamectin, conidia germination was evaluated (germinated conidia/total conidia $\times 100$ ). Viability with mineral oil was determined by means of colonies quantification after 3 days of incubation. The effect of pesticides on conidial germination was determined by plating $200 \mu \mathrm{l}$ of a suspension of $1 \times 10^{3}$ conidia $/ \mathrm{ml} 0.02 \%(\mathrm{v} / \mathrm{v})$ Tween 80 , onto 9-cm Petri dish diameter with 2\% PDA culture medium (Oxoid $\left.{ }^{\mathrm{TM}}\right)$, which containing pesticides in the concentrations was indicated. Plates were incubated at $25^{\circ} \mathrm{C}$ for $24 \mathrm{~h}$ in the dark. Four replicates were performed and 200 spores per plate were counted.

The effect of pesticides on mycelial growth was evaluated by placing a $0.7-\mathrm{cm}$ disc with a mycelium 4 days old onto 9-cm Petri dish diameter with PDA solid medium $\left(\right.$ Oxoid $^{\mathrm{TM}}$ ) containing pesticides in the concentrations

Table 1 Percentage of Diaphorina citri mortality under controlled conditions with different EPF

\begin{tabular}{ll}
\hline Treatments & Mortality (\%) \\
\hline Control & $20.8 \pm 8.7 \mathbf{a}$ \\
Beauveria bassiana $\mathbf{2 0 6 7}$ & $85.9 \pm 3.8 \mathbf{b}$ \\
B. bassiana $\mathbf{2 1 2 1}$ & $84.8 \pm 5.2 \mathbf{b}$ \\
Metarhizium anisopliae 2411 & $82.8 \pm 10 \mathbf{b}$ \\
\hline
\end{tabular}

Averages followed by different letters differ significantly $(p<0.05)$ 

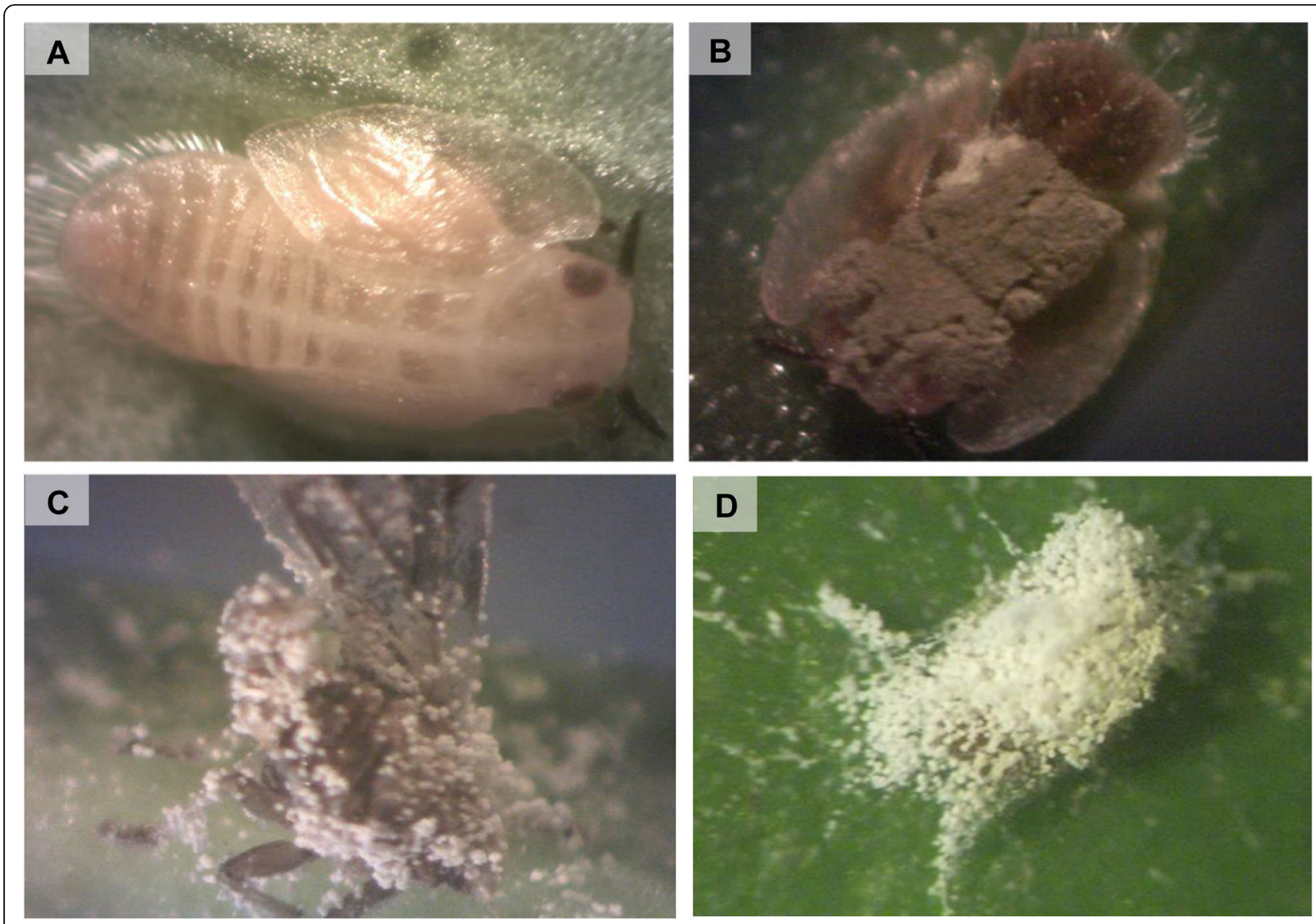

Fig. 1 Fungal infection of Diaphorina citri. a Control nymph of Diaphorina citri. b Nymph with Metarhizium anisopliae 2411. c Adult with Beauveria bassiana 2067. d Nymph with B. bassiana 2067

indicated. Inoculated media were incubated at $25^{\circ} \mathrm{C}$ for 8 days, and the diameter of the colony was daily recorded. Four replicates of each assay were performed. Kruskal-Wallis Test $(\alpha=0.05)$ was used to evaluate the effect of pesticides on conidial germination and mycelial growth.

\section{Results}

Under controlled conditions, the percentage of insect mortality produced after a single application of the EPF that evaluated on the 5th day and varied between 82.8 and $85.9 \%$ compared to $20.8 \%$ of mortality in the controls (Table 1).

Significant differences $(p<0.05)$ were found in insect mortality between the control and treatments of EPF. In contrast, non-significant difference was observed among the different fungal strains. The results indicated that the 3 fungi assayed showed biocontrol activity against $D$. citri in controlled conditions. The performance of the two strains of $B$. bassiana evaluated under controlled conditions was very similar. The strain (B. bassiana 2067) was selected for further assays. Under semi-field conditions, significant differences $(p<0.05)$ in insect mortality were observed between the control and the treatments with EPF. At assessment moment, development of the EPF was observed on D. citri nymphs and adults (Fig. 1). The infection and mortality of D. citri caused by the $M$. anisopliae 2411 strain was significantly higher than that of B. bassiana 2067, 78.9, and 51\%, respectively (Table 2).

In all cases, an effect of temperature on the viability of the spores was observed. Significant differences $(p<$ 0.05 ) were found in the viability of $B$. bassiana and $M$. anisopliae strains. B. bassiana 2067 had above $80 \%$ of viability between 15 and $30^{\circ} \mathrm{C}$ (Table 3).

Table 2 Percentage of Diaphorina citri mortality with different treatments under semi-field conditions

\begin{tabular}{ll}
\hline Treatments & Mortality (\%) \\
\hline Control & $12.3 \pm 10.4$ a \\
Beauveria bassiana 2067 & $51.0 \pm 17.2$ c \\
Metarhizium anisopliae 2411 & $78.9 \pm 11.2$ b
\end{tabular}

Averages followed by different letters differ significantly $(p<0.05)$ 
Table 3 Spores viability (germination percentage) at different temperatures

\begin{tabular}{llllll}
\hline Strain & \multicolumn{5}{l}{ Temperature $\left({ }^{\circ} \mathbf{C}\right)$} \\
\cline { 2 - 6 } & $\mathbf{1 5}$ & $\mathbf{2 0}$ & $\mathbf{2 5}$ & $\mathbf{3 0}$ & $\mathbf{3 5}$ \\
\hline Beauveria bassiana $\mathbf{2 0 6 7}$ & $80.7 \pm 6.7 \mathbf{a}$ & $97.5 \pm 2.2 \mathbf{b}$ & $98.4 \pm 1.1 \mathbf{b}$ & $99.3 \pm 0.7 \mathbf{b}$ & $0.3 \pm 0.7 \mathbf{c}$ \\
B. bassiana $\mathbf{2 1 2 1}$ & $93.2 \pm 2.1 \mathbf{a}$ & $92.9 \pm 6.3 \mathbf{a}$ & $99.5 \pm 0.6 \mathbf{b}$ & $99.8 \pm 0.4 \mathbf{b}$ & $0.0 \pm 0.0 \mathbf{c}$ \\
Metarhizium anisopliae $\mathbf{2 4 1 1}$ & $0.0 \pm 0.0 \mathbf{a}$ & $86.3 \pm 5.5 \mathbf{b c}$ & $92.1 \pm 3.1 \mathbf{~ b}$ & $75.5 \pm 2.8 \mathbf{c}$ & $0.3 \pm 0.6 \mathbf{a}$ \\
\hline
\end{tabular}

Averages followed by different letters differ significantly $(p<0.05)$

$M$. anisopliae spores, however, were not able to germinate at $15^{\circ} \mathrm{C}$, and their viability was reduced considerably at $30^{\circ} \mathrm{C}$. The spores of all strains evaluated were not viable at $35^{\circ} \mathrm{C}$.

Both strains of EPF (B. bassiana and M. anisopliae) had very low virulence against the predators. Nonsignificant effect of EPF on $H$. axyridis was observed. Fungi were able to infect adults, but the mortality rate was low. No effect of the fungi was observed on $H$. axyridis larvae when inoculated with B. bassiana or M. anisopliae, and it was even observed that they completed their cycle reaching the adult stage (Fig. 2). Although both fungi were pathogenic against $C$. externa, their virulence was low. Adult insects were more susceptible to M. anisopliae infection than larvae (Fig. 3).

All conventional pesticides showed a fungistatic effect on both fungi decreasing the viability of spores. Copper oxychloride affected the viability of the $B$. bassiana and M. anisopliae spores (Table 4). However, at the lowest concentration of copper, non-significant differences were observed in the viability (germination) of the conidia with respect to the control for either of the two strains.

Abamectin caused a decrease in spore germination of M. anisopliae and B. bassiana (Table 5).
The 3 concentrations showed significant differences in the viability of the $M$. anisopliae spores with respect to the control. Although the viability of B. bassiana spores remained above $90 \%$ in all treatments, the highest concentration of abamectin slightly decreased the viability of the spores showing, significant differences than the control. At any concentration of mineral oil, nonsignificant differences on spore viability, between control and $M$. anisopliae treatments $(p=0.959>0.05)$ or $B$. bassiana ( $p=0.119>0.05$ ), were observed (Table 6).

As shown in Figs. 4 and 5, all pesticides affected fungal growth, showing significant differences between the control and all treatments for B. bassiana and M. anisopliae. In both cases, copper oxychloride produced the greatest reduction in growth, while mineral oil had a low effect on mycelial growth. On the other hand, it was observed that abamectin significantly affected the growth of $B$. bassiana and M. anisopliae.

\section{Discussion}

Conidial formulations of $B$. bassiana and $M$. anisopliae were able to infect and kill $D$. citri with similar virulence under controlled conditions. However, M. anisopliae conidia were more virulent under semi-field conditions.

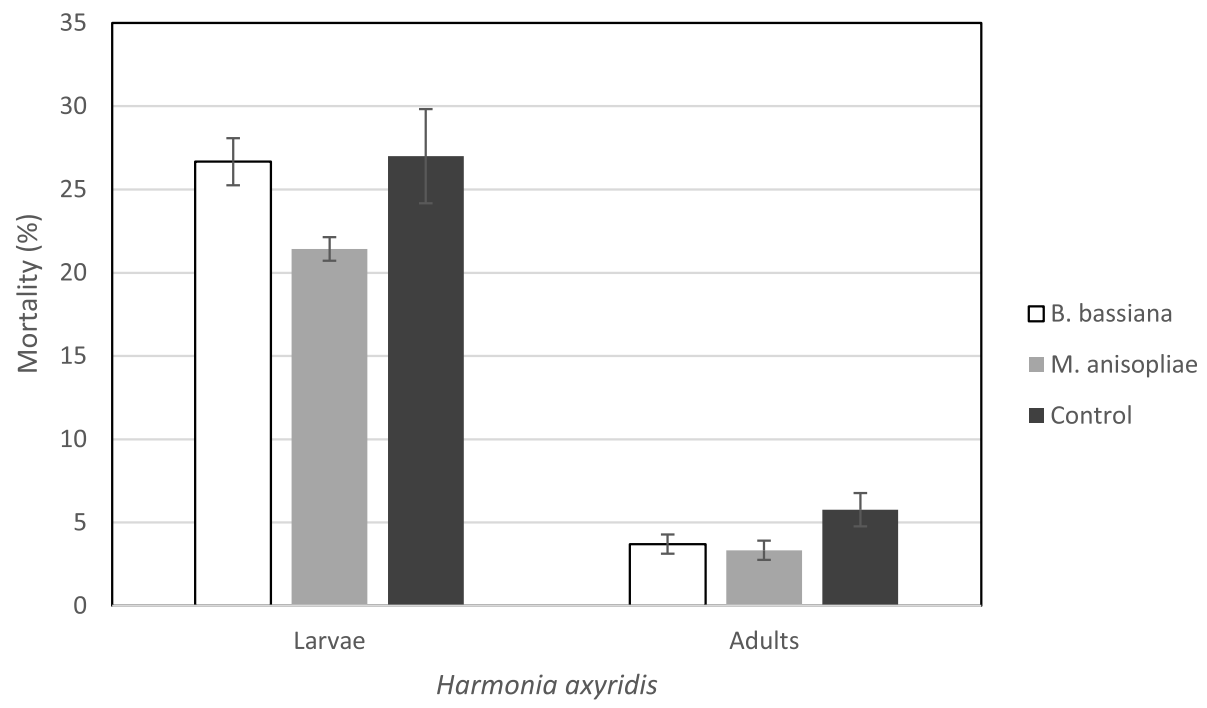

Fig. 2 Mortality percentage of larvae and adults of Harmonia axyridis with entomopathogenic fungi 


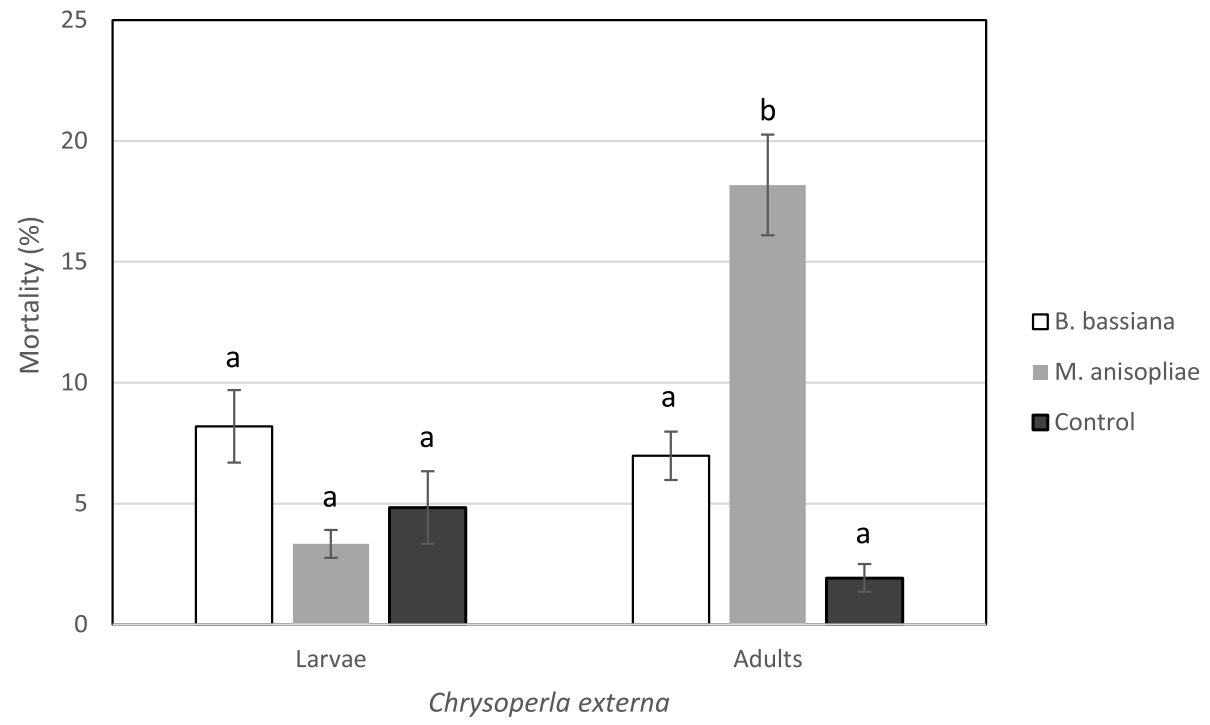

Fig. 3 Mortality percentage of larvae and adults of Cycloneda externa with entomopathogenic fungi

The highest virulence of $M$. anisopliae may be due to its pigmented conidia that offer its UV resistance or to the favorable environmental conditions for its development during the assay. In any case, both species showed high mortality rates of $D$. citri in a short time under laboratory and semi-field conditions, so that either one or both species could be used. To protect the conidia from the negative effects of UV radiation and dryness, a formulation could probably allow obtaining more successful results.

Lezama-Gutiérrez et al. (2012) and Ausique et al. (2017) reported high mortality rates of D. citri nymphs and adults under field conditions, using $M$. anisopliae and B. bassiana, and demonstrating their potential as a biological control agent. Although this study evaluated the direct effects (mortality) on D. citri individuals, indirect effects such as decreasing feeding activity could also occur, as reported by Avery et al. (2011). They suggested that when I. fumosorosea decreases the feeding activity of D. citri, adults may reduce the ability of HLB transmission. Obtained results showed that the spray application method was suitable, as found by Majeed et al. (2017). This could be due to the behavior of D. citri nymphs that aggregate in young shoots and have little

Table 4 Viability (germination percentage) of the spores according to the different treatments with copper oxychloride

\begin{tabular}{lllll}
\hline Fungal species & \multicolumn{4}{l}{ Copper oxychloride concentration (g/l) } \\
\cline { 2 - 5 } & $\mathbf{0}$ & $\mathbf{1 . 7 5}$ & $\mathbf{2 . 5 0}$ & $\mathbf{3 . 2 5}$ \\
\hline $\begin{array}{l}\text { Beauveria bassiana } \\
\mathbf{2 0 6 7}\end{array}$ & $99.3 \pm 0.6 \mathbf{a}$ & $98.8 \pm 1.1 \mathbf{a}$ & $0.0 \pm 0.0 \mathbf{b}$ & $0.0 \pm 0.0 \mathbf{~ b}$ \\
$\begin{array}{l}\text { Metarhizium } \\
\text { anisopliae 2411 }\end{array}$ & $90.3 \pm 2.2 \mathbf{a}$ & $88.9 \pm 4.8 \mathbf{a}$ & $0.0 \pm 0.0 \mathbf{b}$ & $0.0 \pm 0.0 \mathbf{~ b}$ \\
\hline
\end{tabular}

Averages followed by different letters in a row differ significantly $(p<0.05)$ movement in the plant. Consequently, nymphs become a good target for fungal conidia impact. Gregarious behavior can also facilitate the transmission of spores among individuals improving new infection events (Conceschi et al. 2016).

Both fungal species showed a high viability of the conidia between 20 and $30^{\circ} \mathrm{C}$, which could lead to a successful performance in nature. In this temperature range, infections with $D$. citri occurred mostly in the field. In addition, it is very important to consider the interaction of EPF and the predators of D. citri in order to minimize the impact on non-target species and maximize the mortality of $D$. citri. The obtained results showed that both strains of EPF (B. bassiana and $M$. anisopliae) had very low virulence against the natural predators of D. citri.

Similarly, several studies about the interactions between EPF and other natural enemies (parasitoids and predators) have been performed worldwide (Roy and Pell 2000; Bayissa et al. 2016). In particular, the interactions between coccinellid and lacewing species and the EPF have been studied. In the case of coccinellids, the most susceptible stage of infection by $B$. bassiana was the 1st larval instar, being mortality in the other

Table $\mathbf{5}$ Viability (germination percentage) of the spores according to the different treatments with abamectin

\begin{tabular}{lllll}
\hline Fungal species & \multicolumn{4}{l}{ Abamectin concentration $(\boldsymbol{\mu l} / \mathbf{l})$} \\
\cline { 2 - 5 } & $\mathbf{0}$ & $\mathbf{3 5 0}$ & $\mathbf{5 0 0}$ & $\mathbf{6 5 0}$ \\
\hline $\begin{array}{l}\text { Beauveria } \\
\text { bassiana 2067 }\end{array}$ & $99.2 \pm 1.2$ a & $97.6 \pm 0.4 \mathbf{a}$ & $96.9 \pm 1.4 \mathbf{a}$ & $91.5 \pm 1.6 \mathbf{~ b}$ \\
$\begin{array}{l}\text { Metarhizium } \\
\text { anisopliae 2411 }\end{array}$ & $96.3 \pm 0.6 \mathbf{a}$ & $64.9 \pm 6.5 \mathbf{b}$ & $35.0 \pm 5.7 \mathbf{c}$ & $23.8 \pm 3.3 \mathbf{c}$ \\
\hline
\end{tabular}

Averages followed by different letters in a row differ significantly $(p<0.05)$ 
Table 6 Viability (colonies number) of the spores according to the different treatments with mineral oil

\begin{tabular}{lllll}
\hline Fungal species & \multicolumn{4}{l}{ Mineral oil concentration (ml/l) } \\
\cline { 2 - 5 } & $\mathbf{0}$ & $\mathbf{1 2 . 2 5}$ & $\mathbf{1 7 . 5}$ & $\mathbf{2 2 . 7 5}$ \\
\hline $\begin{array}{l}\text { Beauveria bassiana } \\
\mathbf{2 0 6 7}\end{array}$ & $227 \pm 10$ & $236 \pm 10$ & $239 \pm 11$ & $217 \pm 16$ \\
$\begin{array}{l}\text { Metarhizium } \\
\text { anisopliae } \mathbf{2 4 1 1}\end{array}$ & $142 \pm 16$ & $143 \pm 16$ & $138 \pm 17$ & $141 \pm 13$ \\
\hline
\end{tabular}

stages very low (Scorsetti et al. 2017). In the case of lacewings, Castro López and Martínez Osorio (2019) observed that the 1 st instar $C$. externa of larvae were more susceptible to infection with $B$. bassiana and $M$. anisopliae, and the infection was very low in the other stages of development. The mean mortality rates observed were under 15 and $10 \%$ for B. bassiana and $M$. anisopliae, respectively. The results suggest that EPF and predators were compatible and that the simultaneous use of these biological control agents in an integrated pest management program is possible for $D$. citri.

The use of selected insecticides and fungicides for their application during the pre-harvest in citrus trees should be considered to determine the moment of application of the EPF. In Uruguay, copper oxychloride, mineral oil, and abamectin are applied for either orange or tangerine. In this study, an effect of these conventional pesticides on the development of fungi was observed; therefore, fungi and pesticides should be applied at different times, except mineral oil, which can be applied together with EPF.

Several EPF have been investigated for the control of $D$. citri. Among them, I. fumosorosea and B. bassiana have received the highest interest, with commercial products registered or in process, at several countries of the world (Gandarilla-Pacheco et al. 2013; Ausique et al. 2017).

The efficacy of certain fungal species against nymphs and adults of the Asian citrus psyllids has been reported. However, most of these studies were performed under laboratory conditions or only reported scattered results from field trials (Avery et al. 2011; Lezama-Gutiérrez et al. 2012; Stauderman et al. 2012).

Since in the present study, the successful use of $B$. bassiana 2067 and M. anisopliae 2411 to induce high levels of mortality of $D$. citri nymphs and adults under laboratory and semi-field conditions have been shown, it could be consider that it constitute an advance for the friendly environmental control of HLB.

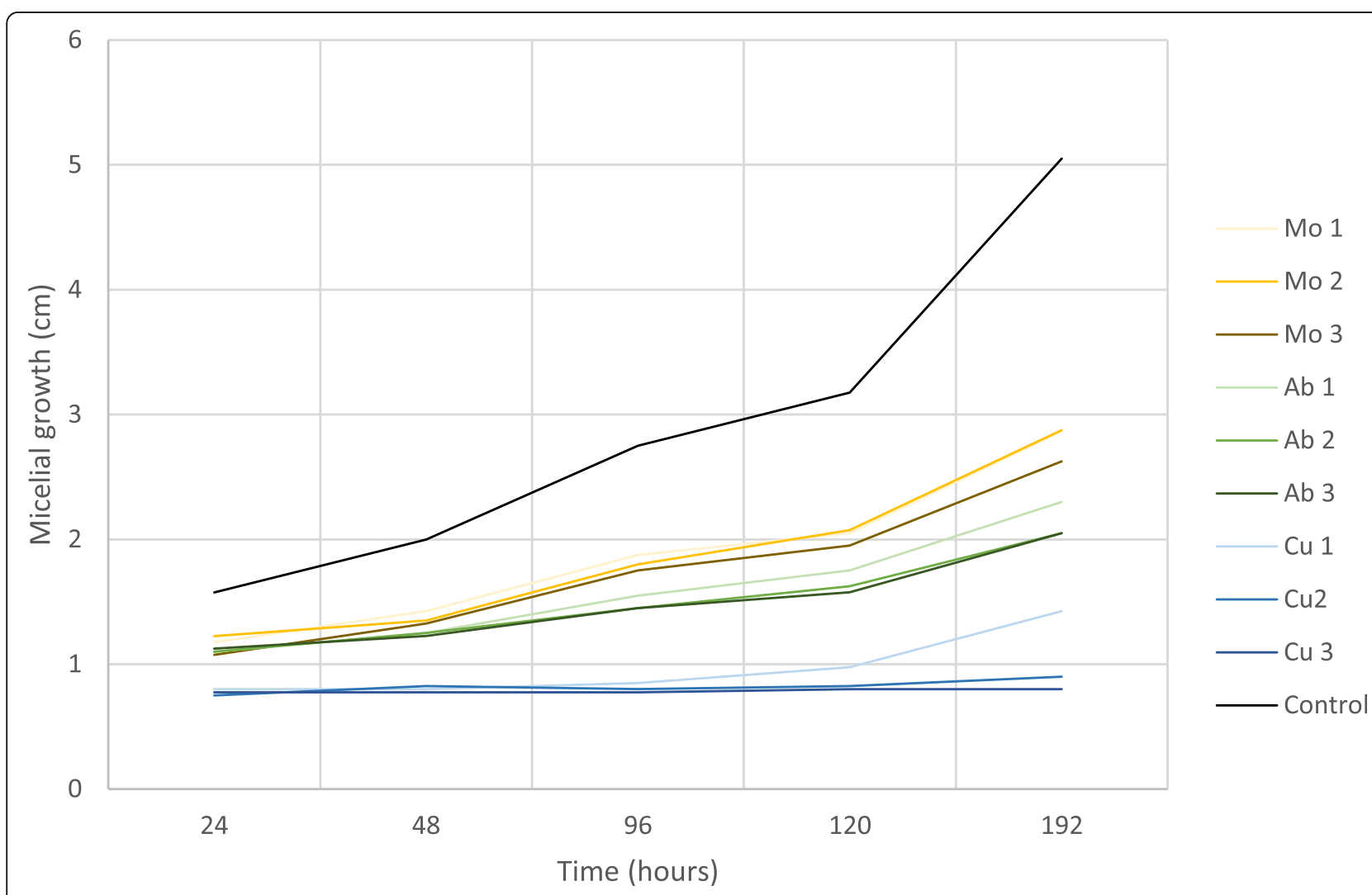

Fig. 4 Growth of Beauveria bassiana 2067 in media containing different concentrations of pesticides (Mo: mineral oil, Ab: abamectin, Cu: copper

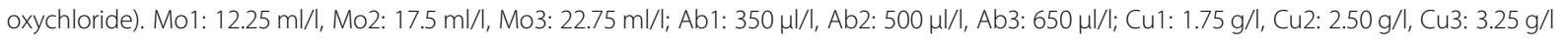




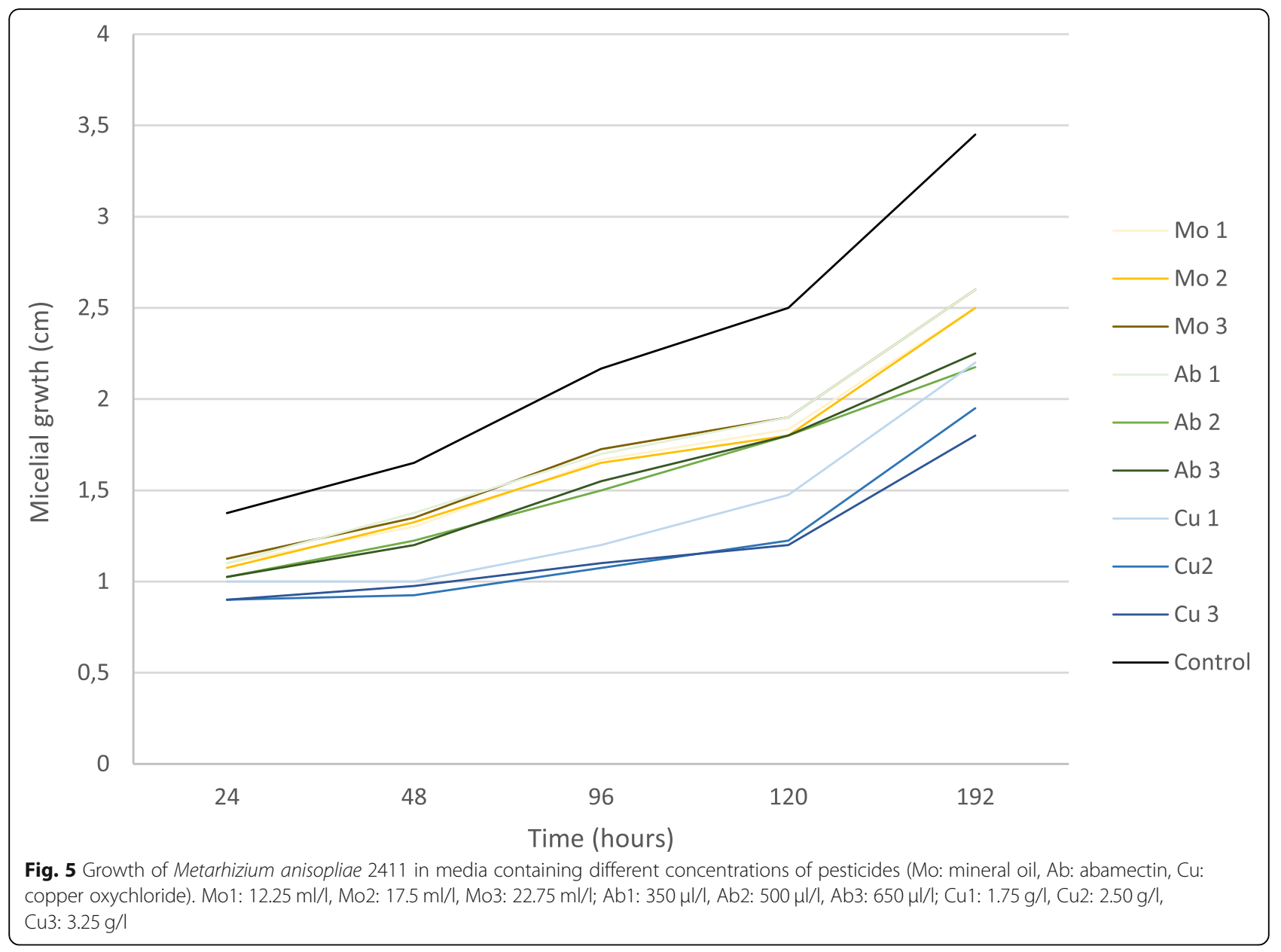

\section{Conclusion}

The strains of EPF B. bassiana $(2067,2121)$ and M. anisopliae (2411) showed promising results for their application as a bio-control agent against $D$. citri. Both strains of fungi showed also a very low virulence against the predators coccinellids and lacewings, and consequently, they could be used together in an integrated pest management program.

\section{Abbreviations}

HLB: Huanglongbing; EPF: Entomopathogenic fungi; PDA: Potato dextrose agar

\section{Acknowledgements}

We thank the Instituto Nacional de Investigación Agropecuaria (INIA) Salto Grande that provided materials for this research.

\section{Authors' contributions}

$A B C$ and $S T$ conceived the research. $A B C, E P$, and $S T$ conducted the experiments. $A B C, E P, L B$, and $S T$ contributed to the materials. $A B C$, $L B$, and $S T$ wrote the manuscript. The authors read and approved the final manuscript.

\section{Funding}

The Instituto Nacional de Investigación Agropecuaria - Fondo de Promoción de Tecnología Agropecuaria (INIA-FPTA) funded this research through the acquisition of materials and payment to researchers.
Availability of data and materials

The data used and analyzed during this study is available from the corresponding author on request.

Ethics approval and consent to participate

Not applicable.

\section{Consent for publication}

Not applicable.

\section{Competing interests}

The authors declare that they have no competing interests.

\section{Author details}

${ }^{1}$ Sección Micología, Facultad de Ciencias-Universidad de la República, Montevideo, Uruguay. ${ }^{2}$ Unidad de Entomología, Facultad de Agronomía-Universidad de la República, Montevideo, Uruguay.

Received: 23 September 2020 Accepted: 29 December 2020 Published online: 14 January 2021

\section{References}

Ausique JJ, Saldarriaga CP, D'Alessandro MR, Concreschi G, Mascarin M, Delalibera Jl (2017) Efficacy of entomopathogenic fungi against adult Diaphorina citri from laboratory to field applications. J Pest Sci 90:947-960. https://doi.org/10. 1007/s10340-017-0846-z

Avery PB, Wekesa WW, Hunter WB, Hall DG, Mckenzie CL, Osborne LS, Powell CA, Rogers ME (2011) Effects of the Isaria fumosorosea (Hypocreales: Cordycipitaceae) on reduced feeding and mortality of the Asian citrus psyllid, Diaphorina citri (Hemiptera: Psyllidae). Biocontrol Sci Tech 21(9):1065-1078 
Bayissa W, Ekesia S, Mohameda SA, Kaayab GP, Wagachab JM, Hannac R, Maniania NK (2016) Interactions among vegetable infesting aphids, the fungal pathogen Metarhizium anisopliae (Ascomycota: Hypocreales) and the predatory coccinellid Cheilomenes lunata (Coleoptera: Coccinellidae). Biocontrol Sci Tech 26(2):274-290. https://doi.org/10.1080/09583157.2015.1099148

Bernal R (1991) Diaphorina citri (Homoptera: Psyllidae) nuevo insecto detectado en montes cítricos en el área de Salto, Uruguay. Instituto Nacional de Investigación Agropecuaria. Hoja de divulgación No 25. http://www.ainfo. inia.uy/digital/bitstream/item/1427/1/111219240807151515.pdf

Bové JM (2006) Huanglongbing: a destructive, newly emerging, century old disease of citrus. J Plant Pathol 88:7-37. https://doi.org/10.4454/jpp.v88i1.828

Castro López MA, Martínez Osorio JW (2019) Compatibility of Beauveria bassiana and Metarhizium anisopliae with Chrysoperla externa depredator of Trialeurodes vaporariorum. Chil J Agric Anim Sci 35(1):38-48

Conceschi MR, D'Alessandro CP, de Andrade MR, Garcia Borges Demétrio C, Delalibera II (2016) Transmission potential of the entomopathogenic fungi Isaria fumosorosea and Beauveria bassiana from sporulated cadavers of Diaphorina citri and Toxoptera citricida to uninfected D. citri adults. BioControl 61:567-577. https://doi.org/10.1007/s10526-016-9733-4

DIEA (2019) Anuario Estadístico Agropecuario, Ministerio de Ganadería Agricultura y Pesca. Uruguay

Gandarilla-Pacheco FL, Gálan-Wong LJ, Arroyo Jl, Rodríguez-Guerra R, QuinteroZapata I (2013) Optimization of pathogenicity tests for selection of native isolates of entomopathogenic fungi isolated from citrus growing areas of México on adults of Diaphorina citri Kuwayama (Hemiptera: Liviidae). Fla Entomol 96(1):187-195

Hesketh H, Roy HE, Eilenberg J, Pell JK, Hails RS (2010) Challenges in modelling complexity of fungal entomopathogens in semi-natural populations of insects. BioControl 55:55-73

Lezama-Gutiérrez R, Molina-Ochoa J, Chávez-Flores O, Ángel-Sahagún CA, Skoda SR, Reyes-Martínez G, Barba-Reynoso M, Rebolledo-Domínguez O, RuízAguilar GML, Foster JE (2012) Use of the entomopathogenic fungi Metarhizium anisopliae, Cordyceps bassiana and Isaria fumosorosea to control Diaphorina citri (Hemiptera: Psyllidae) in Persian lime under field conditions. Int J Trop Insect Sci 32(1):39-44. https://doi.org/10.1017/S1742758412000069

Lopes SA, Luis QB, Oliveira HT, Frare GF, Martins EC, Ayres AJ (2013) HLB research in Brazil - from etiology to disease management. In: Proceedings of the $19^{\text {th }}$ conference IOCV, pp 47-50

Majeed MZ, Fiaz M, Ma C-S, Afzal M (2017) Entomopathogenicity of three Muscardine fungi, Beauveria bassiana, Isaria fumosorosea and Metarhizium anisopliae, against the Asian Citrus Psyllid, Diaphorina citri Kuwayama (Hemiptera: Psyllidae). Egypt J Biol Pest Control 27(2):211-215

Naeem A, Afzal MBS, Freed S, Hafeez F, Zaka SM, Ali Q, Anwar HZ, Iftikhar A, Nawaz M (2019) First report of thiamethoxam resistance selection, cross resistance to various insecticides and realized heritability in Asian citrus psyllid Diaphorina citri from Pakistan. Crop Prot 121:11-17. https://doi.org/10. 1016/j.cropro.2019.03.004

Orduño-Cruz N, Guzmán-Franco AW, Rodríguez-Leyva E, Alatorre-Rosas R, González-Hernández H, Mora-Aguilera G (2015) In vivo selection of entomopathogenic fungal isolates for control of Diaphorina citri (Hemiptera: Liviidae). Biol Control 90:1-5. https://doi.org/10.1016/j.biocontrol.2015.05.011

Pechi E, Aguirre A, Cáceres S, Asplanato G (2016). Identificación y análisis faunístico de enemigos naturales asociados a D. citri (Hemiptera: Liviidae). Avances de investigación de Diaphorina citri. Jornada de divulgación. Programa de Investigación en producción citrícola INIA Salto Grande.

Qureshi JA, Kostyk BC, Stansly PA (2014) Insecticidal suppression of Asian Citrus Psyllid Diaphorina citri (Hemiptera: Liviidae) vector of huanglongbing pathogens. PLoS One 9(12):e112331. https://doi.org/10.1371/journal.pone. 011233

Roy H, Pell JK (2000) Interactions between entomopathogenic fungi and other natural enemies: implications for biological control. Biocontrol Sci Tech 10(6): 737-752. https://doi.org/10.1080/09583150020011708

Scorsetti AC, Pelizza S, Fogel MN, Vianna F, Schneider MI (2017) Interactions between the entomopathogenic fungus Beauveria bassiana and the neotropical predator Eriopis connexa (Coleoptera: Coccinellidae): implications in biological control of pest. J Plant Prot Res 57(4):389-395. https://doi.org/ 10.1515/jppr-2017-0053

Stauderman K, Avery P, Aristizábal L, Arthurs S (2012) Evaluation of Isaria fumosorosea (Hypocreales: Cordycipitaceae) for control of the Asian citrus psyllid, Diaphorina citri (Hemiptera: Psyllidae). Biocontrol Sci Tech 22(7):747-761
Tian F, Wang Z, Li C, Liu J, Zeng X (2018) UDP-glycosyltransferases are involved in imidacloprid resistance in the Asian citrus psyllid, Diaphorina citri (Hemiptera: Lividae). Pestic Biochem Physiol 154:23-31. https://doi.org/10. 1016/j.pestbp.2018.12.010

\section{Publisher's Note}

Springer Nature remains neutral with regard to jurisdictional claims in published maps and institutional affiliations.

\section{Submit your manuscript to a SpringerOpen ${ }^{\circ}$ journal and benefit from:}

- Convenient online submission

- Rigorous peer review

- Open access: articles freely available online

High visibility within the field

- Retaining the copyright to your article

Submit your next manuscript at $\boldsymbol{\sim}$ springeropen.com 